\title{
Narrative Inquiry: Honouring the Complexity of the Stories We Live
}

\author{
Carl Leggo
}

University of British Columbia

\begin{abstract}
Narrative inquiry focuses on the composition of a story as a way to represent experiences. A challenge for narrative researchers is how to compose a story that represents experiences truthfully while also acknowledging that in all our narrative research we can never tell the whole story. There are always far more experiences than we can narrate in the complex and wide-ranging experiences that each of us lives daily. This paper considers the complexity of researching lived stories in order to invite readers to enter into an ongoing and energetic dialogue. I want to honour the multiplicity, meaning-making, and mystery that are at the heart of the searching in narrative research.
\end{abstract}

Wherever there are humans there appear to be stories.

(Cobley, 2001)

Storytelling is an attempt to deal with and at least partly contain the terrifyingly haphazard quality of life. (Fulford, 1999)

Narrative inquiry...is one of trying to make sense of life as lived. (Clandinin \& Connelly, 2000)

Narrative inquiry is a research methodology rooted firmly in a wide range of philosophical, psychological, phenomenological, poetic, and pedagogic perspectives and imperatives. Narrative inquiry is often used in the social sciences, including education. Many related but diverse approaches are used in narrative inquiry, including autobiography, biography, ethnography, autoethnography, phenomenology, hermeneutics, action research, memoirs, case studies, and life-writing. All the approaches focus on the composition of a story as a way to represent experiences. One of the challenges that narrative researchers confront is how to compose a story that represents experiences

Carl Leggo is an Associate Professor in the Department of Language and Literacy Education at the University of British Columbia. 
truthfully while also acknowledging that in all our narrative research we can never tell the whole story. There are always far more experiences than we can narrate.

Any story we tell will always be a fragment of the complex and wideranging experiences that each of us lives daily in our bodies and imaginations, the experiences we live daily in interconnections with family, colleagues, and community. As Kelly (1997) states, "truth is multiple—and always ever partial." So, in our narrative inquiry, we need to be constantly aware of the complexity of the stories we live. I agree with Strong-Wilson (2004) who notes that "a narrative is not simply experience transformed into words on a page." This paper is a rumination on the complexity of researching lived and living stories. I do not present an empirical research study as the focus of the paper or try to exhaust the scholarly literature that informs the issues in this essay. Instead, I reflect on a few issues regarding the complexity of narrative research by engaging in a dialogue with some instructive and some intriguing writers, and I include a few brief stories from my own research to illustrate the main themes of the paper. Basically, I hope to invite readers to consider the issues and to enter into an ongoing and energetic dialogue.

So, I begin with an anecdote. I recently returned to Roberts' Arm, Newfoundland, where I began my teaching career in 1976. I taught at R. W. Parsons Collegiate for two years. I was the classroom teacher for grade seven, teaching a wide range of curricular subjects, including English, social studies, physical education, religious studies, and health. In my first year I taught 48 students. Those first two years of teaching represent a significant foundation for my subsequent practice as a teacher, both in school and university classrooms. Since 1976, I have written a number of narratives about my teaching experiences in Robert's Arm. Last summer when I returned for a reunion, I met one of my former teaching colleagues. Ryan said, "What I remember most about you is the day you walked into the staffroom, and banged an armful of books down on the table, and declared, 'I refuse to devote my life to the Nicky Normores of the world."' He laughed, and I chuckled. I didn't tell him that in the quarter century since I left Roberts' Arm, I had not once remembered my declaration of frustration about Nicky Normore. But with my colleague's recollection, I too remembered Nicky Normore, recalling how little he wanted to be in school, how little he ever wrote or contributed or cared, how exasperated I often was with his lack of willingness to participate in the life of the classroom. Nicky Normore didn't care about school, and I could do nothing to change his mind.

What I find most intriguing about my colleague's recollection of my frustration with Nicky Normore is that whenever I have recalled my first two 
years of teaching, I have generally regarded myself quite heroically, at least in imagination. I have a few photographs of the time. I participated in winter carnivals and hikes and basketball tournaments and Christmas dramas. I remember myself in numerous guises as energetic, creative, diligent, and caring. But of course, that is only part of the story, a version of the story. As Amis (2000) understands in his memoir titled Experience: "My life, it seems to me, is ridiculously shapeless. I know what makes a good narrative, and lives don't have much of that - pattern and balance, form, completion, commensurateness.". Amis' memoir honours his conviction about storying life by avoiding a seamless narrative. Instead of a linear, coherent memoir, Amis has composed a story that is like a patchwork quilt, full of scraps of letters and journals and photographs. He does not try to tell the story of his life, but instead presents numerous moments or images of his life and invites the reader to make sense of the haphazard journey of a writer's life.

Like Amis, I am eager to engage in practices of narrative research that honour the tangled complexity of lived experience. Winterson (1995) asks, "Are real people fictions?" and then proposes that "we mostly understand ourselves through an endless series of stories told to ourselves by ourselves and others. The so-called facts of our individual worlds are highly coloured and arbitrary, facts that fit whatever fiction we have chosen to believe in." I am encouraged by Winterson's realization that "it may be that to understand ourselves as fictions, is to understand ourselves as fully as we can," because if we are always making up stories and being made up in stories, then there is room for critical and creative transformation. As Aoki (1994) explains: "Whenever I write a story, I not only produce a narrative but I'm reproducing myself. The very narrating acts upon me, and I'm changing." Aoki understands the role of language, discourse, and writing in the construction of identity. I agree with Winterson's (1995) conviction that "a writer must resist the pressure of old formulae and work towards new combinations of language." To understand our story-making as a process of working with language is to attend to Huebner's (1999) challenge to educators to "affirm the significance of the imagination."

Therefore, I contend that narrative researchers should attend to language and the rhetoric of story-making. In this regard, I find valuable Bullough and Pinnegar's (2001) distinction between story and plot. They understand a story as a sequence of events narrated in a linear, chronological order. In other words, a story is a simple and straightforward telling of events. A plot, on the other hand, is a sequence of events that has been arranged in order to evoke in readers a keen sense of emotional engagement. Bullough and Pinnegar note "that most self-studies that rely on autobiography embrace the 
story form rather than the plot lines of fiction." And the same conclusion can be made about most narrative inquiry in education.

Tompkins' (1998) Teaching in a Cold and Windy Place: Change in an Inuit School is a good example of much narrative inquiry in education. Without doubt, it is a valuable book about school leadership, vision, and change. Tompkins explains:

This monograph is the story about a school that in 1987 was failing to meet student needs, and which through many interventions... became four years later a school that was hopeful and productive and well on the way to meeting the needs of all the students in the community. It is written in the form of a detailed narrative in which I try to record and later analyse what I did as principal, and what we did as a staff, to create positive change in the school.

Tompkins worked hard as a principal to create conditions for change, and she paid a great deal of attention to contemporary scholarship and research in making her plans. Her book is a good example of a kind of narrative research where the researcher tells a story of experience in a straightforward, linear pattern with an emphasis on analysis and interpretation. Tompkins presents details of events, decisions, implementations, and changes. In the end, the reader has a clear sense of the shape and direction of the experiences she lived as a principal in one Inuit school during several years. Tompkins explains:

It is really only one person's voice, recording school change and then reflecting on the experience, but I hope it will be a voice that speaks honestly and practically in an encouraging way to those educators who really want schools to be sites of success rather than failure.

Tompkins is convinced that educators need to tell their stories in order to reflect on those stories and learn from one another. She concludes: "Research that allows teachers and principals to treat the most important work they do each day as worthy of reflection and study helps give energy, drive, and enthusiasm to doing the job itself."

I admire Tompkins' book, and I eagerly recognize the value of the kind of research and writing that Tompkins has undertaken, but I also contend that there is a need to expand the possibilities of narrative inquiry by paying more attention to the ways that language and rhetoric shape both narration and 
understanding. Therefore, I agree with Bullough and Pinnegar (2001), who acknowledge that "the linearity and simplicity of the story form undoubtedly appeals to the training of teacher educators, particularly for those grounded in the sciences, psychology, teaching methods, and history," but still recommend that more narrative researchers should explore the possibilities of focusing on plot: "The difference between the story form and the plot lines of fiction may be under-appreciated in narrative self-study research. It is our belief that the neglected plot line literary form may enable special insight into learning to teach and teaching."

In related ways, Hutchinson's (1999) Students on the Margins:

Education, Stories, Dignity is a timely reminder to attend to the role of narrative research in classrooms. Hutchinson claims:

Two things schooling can do are, first, to reflect the narrative nature of the self as it develops and, second, to provide a place for students to come to know many different stories as well as articulate their own stories. Both endeavours sustain dignity and hence, the creation of lives.

I especially appreciate Hutchinson's understanding of a core story which she describes as "a way of telling about one's life" that "provides a coherence of meaning to an individual's life experience." Akin to Bullough and Pinnegar's (2001) distinction between story and plot, Hutchinson explains that "a core story represents a fiction of sorts, rather than a description of fact." According to Hutchinson, "coherence, the first characteristic of story, is, in part, the creation of a system of meaning; and meaning is not burdened by historical fact." This comment does not mean that the narrative researcher ignores issues of historical veracity, but only that in telling a narrative, there will always be a focus on patterns and connections among events, emotions, and insights that help to evoke an engaging sense of the experience as lived. In order to compose the narratives that represent our experiences, we will use the resources of imagination, heart, intellect, memory, courage, and wisdom to shape the stories meaningfully.

I have been involved in narrative research for a long time. I have written poems and short fiction that constitute efforts of autobiographical research by attending to connections with family, neighbourhood, and community, and I have written essays about the processes of researching lived experiences, especially as a way to understand issues of teacher identity. (Several relevant publications [Leggo, 1991, 1993, 1995, 1997, 2003] are listed in the references.) I am currently using photography as a way to tell a story. In all 
my writing and researching, I am caught up in what Fulford (1999) calls "the narrative impulse." As I write and tell the narratives of my experiences, and as I read and listen to the narratives of others, I need to be careful that I do not misrepresent the complexity of the experiences. Narrative researchers need to consider how to compose and interpret narratives in rich and full ways that recognize and respect complexity. As Cobley (2001) observes in Narrative, "even the most 'simple' of stories is embedded in a network of relations that are sometimes astounding in their complexity." Cobley also reminds me that "narrative is necessarily bound up with re-presentation." Finally, Cobley notes that "two of the most important features of narrative are the way in which it has been instrumental in the storage of memory and the contribution to the formation of human identity, and the way in which it is thoroughly selective." I am especially intrigued by the relationship between the formation of identity and the ways that "narrative selects some events and omits others" (Cobley, 2001).

In my narrative research I seek to acknowledge the ways that texts construct understanding, and the ways that any research report is a text or a crafted narrative of events, experiences, and emotions. In other words, rhetoric (the art and science of language use) is inextricably involved in the shaping of all research texts. If we consider the discursive practices of the typical education research article in a refereed journal like Brock Education, then the formal rules that govern the rhetoric of published essays include: the use of formal language that is deemed appropriate; critical citations from other refereed publications; a detailed description of an empirical research project; a clear theoretical foundation; and a coherent explanation of relevance for the scholarly field. Discursive expectations, conventions, and rules determine and constrain the possibilities for texts. In order to begin imagining how discursive traditions constrain academic texts, we only need to consider how differently our research might look if we used poetry, film, hypertext, music, or photography, for example, to present our projects and conclusions. My point is simply that texts shape our understandings, and we need to be more self-aware of the ways that we construct texts as artifacts in language, texts that could be constructed in a host of alternative ways.

Narrative research is generally understood as a noun, a product, or a construction, but if attention is paid to the active quality of narrating or researching as verbs, then the focus shifts to the creating and constructing, the writing, that is at the heart of narrative research. The practice of narrative research involves an engagement in active processes of writing. Therefore, the narrative researcher needs to constantly interrogate those processes in order to acknowledge the ways in which writing selects, controls, and even fabricates 
some stories from the multiplicity of possibilities that comprise lived experience. In my narrative research I seek to investigate self-reflexively the ways that knowledge is constructed by developing a textual site where the multiple voices of researcher and research subjects can be heard. Above all, research should stress the ways that any narrative inquiry involves many people, all of whom are involved in living the experience and constructing understandings of the experience. Narrative research should challenge the ways we typically construct knowledge by stressing the ways that the craft of writing shapes and controls the efforts to report experience. Hence, narrative research is an interpretive venture of creative inquiry.

As I write narratives of experiences, I do not want to misrepresent the complexity of the experiences by writing narratives that exclude and silence difference and conflict and confusion in a misdirected zeal to produce tidy linear narratives. Instead, I want to honour the multiplicity and meaning-making and mystery that are at the heart of the searching in my research.

\section{Honouring the Multiplicity}

I found a metaphor for some of my concerns about writing narratives while visiting a toy store where I saw a jigsaw puzzle with 1,000 pieces, each piece with the same shape. All the pieces will fit together in myriad ways, but of course only one rendition of the puzzle will accurately $r e$-present the picture on the box cover. And for the puzzle fan who wants accurate re-presentation, nothing but a faithful version will satisfy. Eventually the patient or devoted puzzler will join the 1,000 pieces of the puzzle in a true re-presentation, and will know the puzzle is finished correctly. Perhaps for too long the authors of narratives have pretended that they are seeking an ideal $r e$-presentation of the events of an experience. Perhaps it would be better to join the pieces and let the product invite interpretation, perhaps best to promote multiple and diverse variations, perhaps best to stray from literal or realistic re-presentation. As I engage in the processes of writing and reading narratives of lived experiences, my own and others, I seek to resist and even subvert unity and closure by acknowledging the multiple pieces and the multiple possibilities for organizing the pieces in myriad ways of significance. My goal is to keep open the processes of investigation and understanding. Clandinin and Connelly (2000) consistently acknowledge the complexity of narrative inquiry. They explain:

Narrative inquiry is a way of understanding experience. It is a collaboration between researcher and participants, over time, in a place or series of places, and in social interaction with milieus. An inquirer enters this matrix in the midst and 
progresses in this same spirit, concluding the inquiry still in the midst of living and telling, reliving and retelling, the stories of the experiences that make up people's lives, both individual and social. Simply stated,...narrative inquiry is stories lived and told.

By acknowledging the multiplicity of different accounts and perspectives and interpretations, disseminating and diverging differences, I risk the possibility of saying nothing more useful than a cliché about how big the world is. Of course, I do not want to speak about narrative research in clichés. Instead I seek to honour the multiplicity of differences that are manifested in lived experiences, always refusing to hide the ragged edges, the pieces that do not fit, the noise, the disjunctures that are all integral parts of the experiences. In an issue of Canadian Journal of Education titled Against the grain:

Narratives of resistance, guest editor de Castell (1993) writes about a "certain exhaustion with 'narratives of redemption' in so much educational theory and research," narratives characterized by "irrepressibly enthusiastic exhortations." Instead of "narratives of redemption," de Castell promotes "narratives of resistance" which are concerned with "impediments, obstacles, insufficiencies, unkept promises, and work not done." De Castell explains: "Education remains a field of discourse governed by the obligation to be 'positive,' and in which, increasingly, no one dares to speak of obstacles, impediments, difficulties without in the same breath expounding on 'solutions.'”.

In light of de Castell's advice, I present the following brief narrative as an illustration of how even an apparently simple narrative can refuse a linear and coherent pattern and instead complicate the understanding of experience. I recently began writing a narrative about a teaching colleague I once knew. I remembered how Ethel stomped through the school corridor like an army marine sergeant determined on intimidating her troop, the enemy, even any four-star generals who had the gumption to show up on Ethel's battleground. About her students, Ethel often said, "You can lead a horse to water, but you can't make it drink. Still, you can almost drown the horse trying to make it drink." I taught with Ethel for six years and I was always scared of her. She was dogmatic, didactic, and dictatorial. Having lost her hair during a childhood illness, she wore a wig, and like her wig, she was wiry and conservative and unchangingexcept in December, when she wore bright green and brighter red stockings, a sharp, scrawny Christmas tree of a woman. She taught math. Her students were afraid of her. I was afraid of her. In my memory, that is generally the way I represent her. Yet if I linger longer in remembering, I recall the needy student who asked Ethel for $\$ 50$ for a graduation dress, and Ethel gave her the money 
with a cheerful command, "Enjoy yourself." And as I persist in remembering, I recall many other stories of Ethel that complicate my understanding of her.

I need to be open to other perspectives and observations. I am always so eager to claim that I know the whole story, when what I really need is to see from multiple perspectives, to understand how others see and know. Every story has multiple possibilities and meanings and resonances. Clandinin and Connelly (2000) remind me about the importance of "being as alert to the stories not told as to those that are." For Mills (1997), "the process of finding a position for oneself within discourse is never fully achieved, but is rather one of constantly evaluating and considering one's position and, inevitably, constantly shifting one's perception of one's position and the wider discourse as a whole."

\section{Honouring the Meaning-making}

I live in the world as a poet. The word poetry is derived from poiein, to make. As a researcher I am a poet or maker. I seek to enter lived experiences with an imaginative openness to the people and activities and dynamics at work and play. I seek to make a story in collaborative dialogue with others, always aware that the story is one of many stories, one of many versions of the story. In this process of story-making I am always concerned with the constructing of the narrative text, and who participates in constructing the narrative text, and how the narrative text is to be presented and interpreted.

As I make meaning out of lived experiences (my own and others) I am an interpreter who stands between the chaos of the experience and the production of a tidy narrative that represents the experience. In the end the narrative becomes one of multiple possible stories. Recently I spent a semester visiting a secondary school in a British Columbia city in order to research the experiences of a grade ten writing class. In addition to observing the teacher and the class, I was provided with ready access to students' portfolios and the teacher's responses to the students' writing. After the semester ended, I had an abiding and nagging sense of having had a memorable experience, but not being sure what the experience really meant or might mean. My most pressing question was, "What do I make of what has happened?" In other words, I wanted to know how to make sense of the experience and how to interpret the experience. I had entered the experience of the writing class with an imaginative openness to the people and activities and dynamics operating in the classroom - or at least I aimed to enter the experience with imaginative openness. In fact, as I reflected on the way I prepared for researching the writing class, I realized that in order to satisfy the demands of a research project ethics review which 
required a clear presentation of my research proposal and plan, I had established some very specific guidelines to bring order to the immense and complex scene of the research. So after the project I was challenged and encouraged by Tyler's (1986) useful explanation of post-modern ethnography:

Because post-modern ethnography privileges "discourse" over "text," it foregrounds dialogue as opposed to monologue, and emphasizes the cooperative and collaborative nature of the ethnographic situation in contrast to the ideology of the transcendental observer. In fact, it rejects the ideology of "observer-observed," there being nothing observed and no one who is the observer. There is instead the mutual, dialogical production of a discourse, of a story of sorts. We better understand the ethnographic context as one of cooperative story-making that... would result in a polyphonic text, none of whose participants would have the final word on the form of the framing story or encompassing synthesis.

I questioned how successfully I met the key qualities of Tyler's (1986) description. I was committed to Tyler's vision, but perhaps still sought to control the creation of the experience too much. For example, some students were invited to talk with me and to share their writing, but not all students. Ultimately the investigation of the writing class was "a story of sorts," but only one of many stories that could have been told. I liked Tyler's notion of "the mutual, dialogical production of a discourse, of a story of sorts" which he calls "a polyphonic text," but I was still concerned with the constructing of the text, and who participates in constructing the text, and how the text is to be presented and interpreted. When the experience ended, and the students went on to other courses, one person remained to make meaning out of the experience. I am the interpreter who stands between the chaos of the experience and the production of a tidy narrative that $r e$-presents the experience. In the end the "story of sorts" becomes one of multiple possible stories, and the story that I, as researcher, am writing now is one more "story of sorts," one more effort of meaning-making.

Now that the experience is finished and the interplay of multiple and polyphonic voices stilled, it is now reconstituted in the voice of the researcher. When I visited the grade ten writing class as a researcher, I was concerned with questions of relations of power: Who writes? Who speaks? Who can write and speak? What are the places where speaking and writing occur? What 
conventions govern and constrain the speaking and writing? What are the dynamics of discourse? I continue to be concerned with these same questions, but there is a tension in my ongoing work, a tension which is suggested in Clifford's (1986) observation that "an interest in the discursive aspects of cultural representation draws attention not to the interpretation of cultural 'texts' but to their relations of production." When I began the research project in the grade ten writing class, I was committed to understanding how discourse shapes knowledge and identity in a pedagogic situation; I was concerned with "relations of production." But now my attention has shifted to a concern with interpretation because I have a responsibility to address the basic question, "What does all this mean?" The research project is over, and I remain to make some sense out of the experiences I have lived with the teacher and the students. As I engage in my efforts of meaning-making, I am reminded of Clifford's (1986) insight that “"cultures'do not hold still for their portraits. Attempts to make them do so always involve simplification and exclusion, selection of a temporal focus, the construction of a particular self-other relationship, and the imposition or negotiation of a power relationship.". Nevertheless, with this understanding to guide me, I still want to make meaning out of the multi-authored text written in the journal entries, written records, field notes, and interview notes generated during the research project. As Fulford (1999) observes, "That's the narrative tradition's great power: the ability to bestow meaning on otherwise disorganized events.". According to Fulford, "Stories inevitably demand ethical understanding. There is no such thing as just a story. A story is always charged with meaning, otherwise it is not a story, merely a sequence of events." Fulford's notion of "ethical understanding" suggests that stories are always composed and interpreted with attention to values and ideology.

But the challenge in narrative research is that our understanding, interpretations, responses, thoughts, even our actions, are all constructed and constrained by the discursive patterns and frames that society permits and authorizes, on the one hand, and excludes and prohibits, on the other. As Mills (1997) explains, "discourses structure both our sense of reality and our notion of our own identity." Hence, the business of meaning-making in narrative inquiry is always necessarily complicated by the vast array of possibilities for making sense out of inchoate experience, on the one hand, and the discursive traditions that constrain meaning-making, on the other. To address this challenge, I look to the practices of interpretive inquiry as demonstrated and explained by Aoki $(1988 ; 1994)$ and Jardine (1992).

Honouring the Mystery 
Sullivan (1995) reminds me that "a life is a puzzle to be decoded, but it is not a solution to the puzzle that one is after; it is an unlayering of the depths of the puzzle so that its mystery can be revealed." Interpretation honours mystery. Of course, the difficulty with all efforts of interpretation is that interpretation is inevitably about standing in the spaces between the experience of mystery and the effort to reveal the mystery. Interpret comes from the Latin word interpretari meaning an agent between two parties, a broker, a negotiator, an interpreter. Therefore, as interpreters we need humility and humour and a sense of skepticism about our word-making. There is always more than we can write and speak. As Clandinin and Connelly (2000) explain, "Narrative inquirers also know that the taken-forgrantedness is never exhausted and that mystery is always just behind the latest taken-for-granted sense making."

According to Jardine (1992), "interpretive inquiry... begins by being 'struck' by something, being 'taken' with it." As a researcher, I resonate with Jardine's view, but I am still concerned with all the "somethings" that do not strike me, that I am not taken with, all the stories that are lived and ignored, not discussed or interpreted or given attention, the stories that remain significantly unwritten. Am I only struck by those things that fit my preconceptions and personality? This is the kind of question that Jardine helps me ask, because his explanation of interpretive inquiry honours the mystery of chaos where plurality, plenitude, and possibility reside: "Interpretive inquiry does not wish literally and univocally to say what this instance is. Rather, it wishes to playfully explore what understandings and meanings this instance makes possible." So, understanding is always tentative and malleable.

In the context of recounting a specific narrative about a new teacher's experience of going to her school for the first time, Jardine ponders, "what is the task of educational inquiry?" with respect to the individual case or incident which elicits in others a sense of identification or familiarity. He asks, "How are we to do justice to this particular episode that happened to a particular teacher at a particular time and place, while at once respecting the undeniable kinship we experience in hearing this teacher's tale?" Jardine proposes that "understood interpretively, such incidents can have a generative and re-enlivening effect on the interweaving texts and textures of human life in which we are all embedded. Bringing out these living interweavings in their full, ambiguous, multivocal character is the task of interpretation." Jardine claims a big task for interpretation. Nevertheless, he is not proposing that interpretation must be full as in complete or whole, 
but that interpretation ought to have the fullness of complexity and richness, lined with ambiguity and multiplicity.

The kind of narrative research that I engage in is focused on language and discourse, and seeks to honour what Aoki (1988) calls "the silent mystery that is teaching." My research is about searching, and returning to the texts of my research, again and again, constantly ready, even hoping, for surprises. As Jardine (1992) reminds us, "interpretive research is...not a method that can be handed over (it is almost impossible to answer a question like 'How do you do hermeneutics?'), but is a practice."

In that practice I have been profoundly influenced by Aoki (1994), who understands that "living in the spaces is what teaching is." For Aoki, "the important thing is to understand that if in my class I have 20 students, then there are 20 interspaces between me and students. These interspaces are spaces of possibilities. So what we allow to happen, what can be constituted and reconstituted in those interspaces is what we mean by life in the classroom." Of course, there are also interspaces between each student and all the others, contributing to an intricate network of lines and spaces of connection and communication, perhaps without end.

According to Clandinin and Connelly (2000), "narrative inquiry is an experience of the experience. It is people in relation studying with people in relation." The important lesson that I learned when I returned to Robert's Arm last summer is that I need to return often to the stories I have lived in order to know the stories in their multiplicity, meaning-making possibilities, and mystery. Each story, each version of a story, each interpretation, each interrogation comprises steps on the living journey that shapes a life. The narrative researcher needs to be bold and imaginative, courageous and skeptical, tentative and exploratory. Clandinin and Connelly (2000) provide wise advice: "A language of wakefulness allows us to proceed forward with a constant, alert awareness of risks, of narcissism, of solipsism, and of simplistic plots, scenarios, and unidimensional characters." In light of Clandinin and Connelly's advice, I find Hutchinson's (1999) direction especially helpful:

Story is relational and reciprocal and, as such, entails moral responsibilities. As we tell stories and listen to stories, we stand in a moral relation to one another. The process itself is reciprocal, that is, I tell a story and you listen, and then you tell a story and I listen. But the notion of reciprocity extends beyond this. Reciprocity does not simply mean 
that we share stories back and forth, but that we have an obligation to listen and tell in ways that will sustain the dignity of one another and avoid domination.

By telling one story, I might preclude many others. For example, I could choose to tell a story in a pattern, such as that of the romantic hero, that silences other possibilities. One story can render other stories invisible or silenced. A story can sustain a position of domination or privilege, instead of opening up possibilities for dialogue. As Kelly (1997) points out, "To tell one story is to silence others; to present one version of self is to withhold other versions of self."

The narrative researcher does not try to pin down truth. Instead, the narrative researcher engages in an ongoing process of questioning, and seeks to represent that questioning in research texts that invite productive readers to continue the questioning. As Fulford (1999) proposes: "Stories, however valuable, may be puzzling as well as engaging...Stories ostensibly begin in order to explain something, or to make an event clear. They turn an incident this way and that, throw several kinds of light on it, surround it with a certain mood - and then put it back in its place, still unexplained." The narrative researcher is eager to engage in ongoing dynamic dialogue where truthfulness can emerge.

\section{References}

Amis, M. (2000). Experience. New York: Hyperion.

Aoki, T. (1988). The sound of pedagogy in the silence of the morning calm: From story to three themes. In Korean studies: Its cross-cultural perspectives, papers of the Sixth International Conference (pp. 692710). Seoul: The Academy of Korean Studies.

Aoki, T. (1994). Interview with Ted Aoki. Teacher, 6(7), 10.

Bullough, Jr., R. V., \& Pinnegar, S. (2001). Guidelines for quality in autobiographical forms of self-study research. Educational Researcher, 30(3), 13-21.

Clandinin, D. J., \& Connelly, F. M. (2000). Narrative inquiry: Experience and story in qualitative research. San Francisco: Jossey-Bass.

Clifford, J. (1986). Introduction: Partial truths. In J. Clifford \& G. E. Marcus (Eds.), Writing culture: The poetics and politics of ethnography (pp. 214). Berkeley: University of California Press.

Cobley, P. (2001). Narrative. London: Routledge. 
De Castell, S. (1993). Introduction: 6 December 1989/1993, Je me souviens. Canadian Journal of Education, 18, 185-188.

Fulford, R. (1999). The triumph of narrative: Storytelling in the age of mass culture. Toronto: Anansi.

Huebner, D. (1999). The lure of the transcendent: Collected essays by Dwayne Huebner. Vicki Hillis (Ed.). Mahwah: Lawrence Erlbaum.

Hutchinson, J. N. (1999). Students on the margins: Education, stories, dignity. Albany: State University of New York Press.

Jardine, D. W. (1992). The fecundity of the individual case: Considerations of the pedagogic heart of interpretive work. Journal of Philosophy of Education, 26(1), 51-61.

Kelly, U. A. (1997). Schooling desire: Literacy, cultural politics, and pedagogy. New York: Routledge.

Leggo, C. (1991). Flowers for the teacher. In J. Parsons \& L. Beauchamp (Eds.), Stories of teaching (pp. 31-33). Richmond Hill: Scholastic.

Leggo, C. (1993). Running in the world upside down. Journal of Educational Thought, 27(1), 83-87.

Leggo, C. (1995). Storing the word/storying the world. English Quarterly. 28(1), 5-11.

Leggo, C. (1997). The story always ends with etc.: Autobiography and poetry. English Quarterly. 29(3,4), 67-86.

Leggo, C. (2003). Backyard quest(ion)s written in stone and water: Alchemic possibilities in the space of the heart. In E. Hasebe-Ludt \& W. Hurren (Eds.), Curriculum intertext: Place/language/pedagogy (pp. 131-148). New York: Peter Lang.

Mills, S. (1997). Discourse. London: Routledge.

Strong-Wilson, T. (2004). Storying experience: What is the role of reflective practice in preservice education? English Quarterly, 36(1), 16-22.

Sullivan, R. (1995). Shadow maker: The life of Gwendolyn MacEwen. Toronto: Harper Collins.

Tompkins, J. (1998). Teaching in a cold and windy place: Change in an Inuit school. Toronto: University of Toronto Press.

Tyler, S. (1986). A post-modern ethnography: From document of the occult to occult document. In J. Clifford \& G. E. Marcus (Eds.), Writing culture: The poetics and politics of ethnography (pp. 122-135). Berkeley: University of California Press.

Winterson, J. (1995). Art objects: Essays on ecstasy and effrontery. Toronto: Alfred Knopf Canada. 